\title{
The determination of highly time resolved and source separated black carbon emission rates using radon as a tracer of atmospheric dynamics (Supplement)
}

$5 \quad$ Asta Gregorič ${ }^{1,2}$, Luka Drinovec ${ }^{1,3}$, Irena Ježek ${ }^{1}$, Janja Vaupotič ${ }^{4}$, Matevž Lenarčič ${ }^{5}$, Domen Grauf $^{5}$, Longlong Wang ${ }^{2}$, Maruška Mole ${ }^{2,6}$, Samo Stanič² ${ }^{\text {, Griša Močnik }}{ }^{1,2,3}$

${ }^{1}$ Aerosol d.o.o., Ljubljana, SI-1000, Slovenia

${ }^{2}$ Centre for Atmospheric Research, University of Nova Gorica, Nova Gorica, SI-5000, Slovenia

${ }^{3}$ Department of Condensed Matter Physics, Jozef Stefan Institute, Ljubljana, SI-1000, Slovenia

${ }^{4}$ Department of Environmental Sciences, Jozef Stefan Institute, Ljubljana, SI-1000, Slovenia

${ }^{5}$ Aerovizija d.o.o., Ljubljana, SI-1000, Slovenia

${ }^{6}$ Quasar Science Resources S.L., ES-28232 Madrid, Spain

Correspondence to: Asta Gregorič (asta.gregoric@aerosol.eu)

1. Source apportionment of $B C$ : Estimation of the site specific $A A E_{T R}$ and $A A E_{B B}$ :

A histogram of absorption Ångström exponent (AAE) derived by Eq. 1 from AE33 measurements for both measurement locations is shown on Fig. S1. For direct comparison, only the time period with available measurements at both locations simultaneously was considered and covers the period from February to May 2017. Winter AAE median values of 1.36 and 1.60 and spring median values of 1.22 and 1.36 are characteristic for Ljubljana (LJ)and Ajdovščina (AJ) location, respectively. Lower AAE values measured in $L J$ correspond well to the urban nature of $L$ measurement site, where stronger influence of traffic on $\mathrm{BC}$ concentrations is expected.

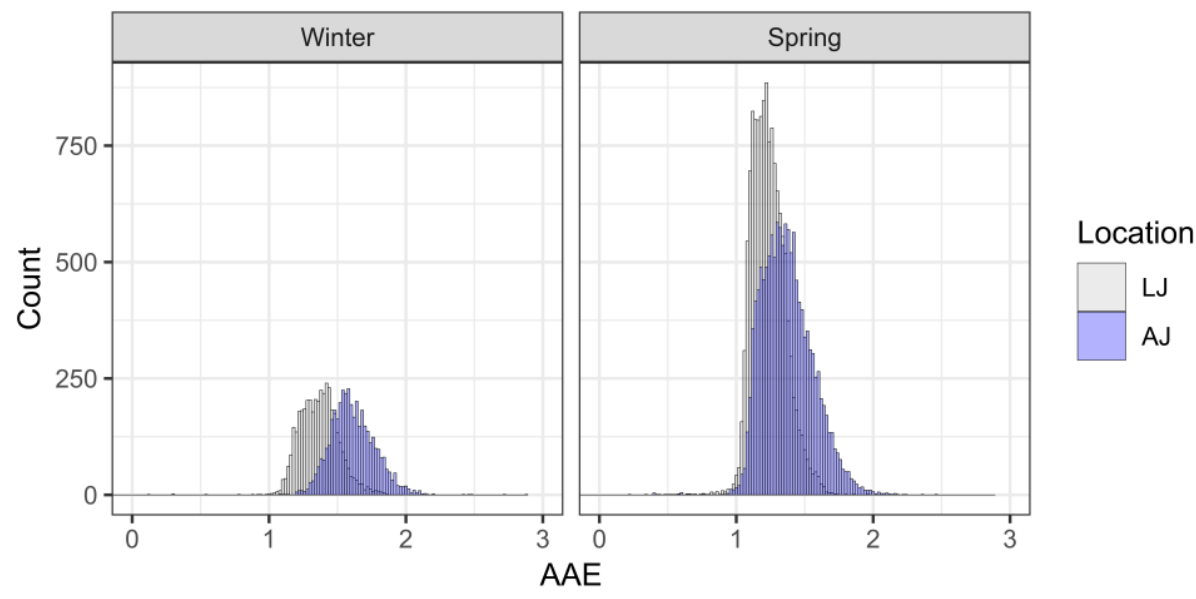

Figure S1: Absorption Ångström exponent (AAE) frequency distributions of 10-minute averages for Ajdovščina (AJ) and Ljubljana (LJ) for the period from February - May 2017 (winter: February, March; spring: April, May). 
The same $A A E_{T R}-A A E_{B B}$ pair of 1.0 and 2.0 was chosen for both measurement locations, based on the evaluation of AAE distribution (Fig. S1). Source apportioned BC concentration (Sandradewi et al., 2008; Zotter et al., 2017) diurnal variation is shown on Fig. $S 2$ for two limiting $A A E_{B B}$ values: 1.7 and 2.0 and fixed $A A E_{T R}=1.0$. The $A A E$ pair of 1.0 and 1.7 results in $B C_{T R}$ and $B C_{B B}$ concentrations presented by blue line, whereas the AAE pair of 1.0 and 2.0 results are presented by red line. Shaded area shows the range of source apportioned concentration between the limiting $A A E_{B B}$ values.

The lower limit of 1.7 for $A A E_{B B}$ is apparently not suitable for $A J$ location, since overall AAE distribution of aerosol mixture in winter frequently exceeds 2.0 (Fig. S1). The source specific AAE values used for source apportionment are representative for the location and type of combustion, they can be interpreted as "average" values at the specific receptor site. The choice of $A A E_{B B}$ needs to fall just below the maximum values seen at this site (a case of exclusive contribution of biomass burning, allowing still some variation of "real" $A A E_{B B}$, which may vary with time to a certain degree, depending on the primary emissions of combustion and the formation of light absorbing secondary organic aerosol (Kumar et al., 2018)). Moreover, an increase of $B C_{\mathrm{BB}}$ causes simultaneous decrease of $B C_{\mathrm{TR}}$. This effect can be clearly observed in the Ajdovščina winter diurnal profile after 21:00, when $B C_{T R}$ unrealistically drops to almost zero (Fig. $\mathrm{S} 2 \mathrm{C}$ ). On the other hand, $A A E_{B B}=2$ results in reasonable diurnal variation of source apportioned $\mathrm{BC}$. In winter, $B C_{\mathrm{TR}}$ and $B C_{\mathrm{BB}}$ concentrations start to increase around 5:00 and exhibit the morning peak between 7:00 and 8:00, when $B C$ is dominated by traffic sources. After daytime dilution in the rising PBL, both $B C_{T R}$ and $B C_{B B}$ start to increase between 16:00 and 17:00 due to decreased mixing in the PBL. $B C_{T R}$ exhibits the afternoon peak around 19:00, whereas $B C_{B B}$ further increases until 21:00.

AAE distribution at $\mathrm{L}$ location is clearly shifted to lower values, as compared to $A J$ location, which can be assigned to stronger contribution of traffic sources. However, by considering only the AAE distribution and the diurnal variation of source apportioned $B C$, without any other independent measurements, it is not possible to define a reliable source specific AAE pair used for source apportionment. Therefore, a suitable AAE pair for source apportionment was evaluated also by reevaluation of subsequently modelled $B C$ emission rate (discussed in Section 3.4). Average $B C$ biomass burning fraction resulting from source apportionment using two different values of $A A E_{B B}$ (1.7 or 2.0$)$ is presented in Table S1. 

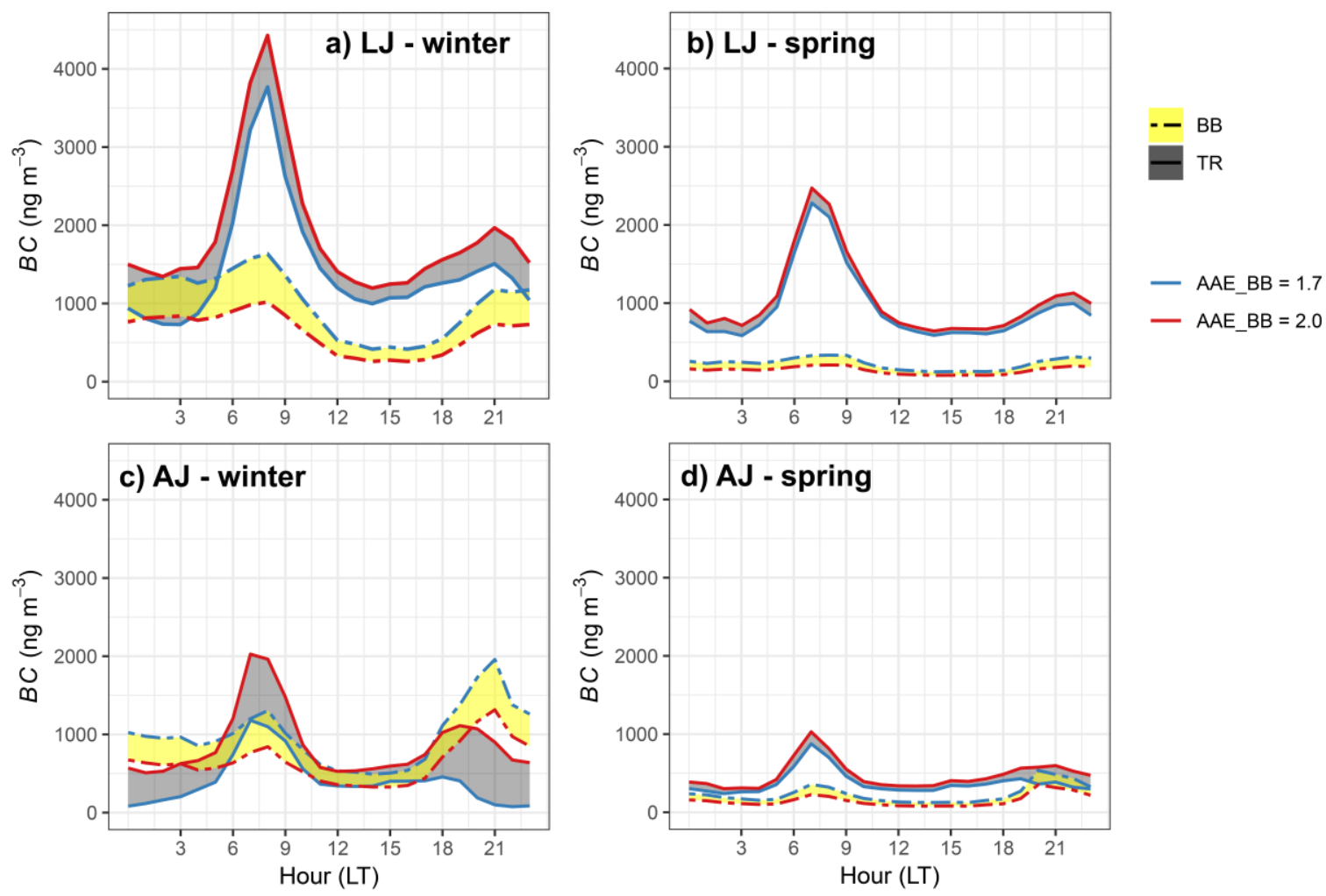

Figure S2: Diurnal variation (local time: CET/CEST) of contribution of traffic $\left(B C_{\mathrm{TR}}\right)$ and biomass burning $\left(B C_{B B}\right)$ to total $B C$ concentration in winter (January - February) and spring (March - April) period for Ljubljana (U) and Ajdovščina (AJ) measurement site, by considering different pairs of absorption Ångström exponents (AAE). $A A E_{T R}$ was fixed to 1.0, $A A E_{B B}$ was set to 1.7 (blue line) and 2 (red line). The shaded area represents a range of $B C_{T R}$ (grey) and $B C_{B B}$ (yellow) concentrations calculated between both extreme values of $A A E_{B B}$. Diurnal variation is derived from 1-minute data by considering median of concentration for specific hour.

Table S1: Average $B C$ biomass burning fraction (BB\%) based on source apportionment using fixed $A A E_{T R}=1.0$ and limit values of 1.7 and 2.0 for $A A E_{B B}$.

\begin{tabular}{|l|l|l|l|l|}
\hline $\begin{array}{l}\text { Measurement } \\
\text { location }\end{array}$ & $\begin{array}{l}\text { Winter } \mathrm{BB} \% \\
\left(\mathrm{AAE} \mathrm{E}_{\mathrm{BB}}=1.7\right)\end{array}$ & $\begin{array}{l}\text { Winter } \mathrm{BB} \% \\
\left(\mathrm{AAE} \mathrm{E}_{\mathrm{B}}=2.0\right)\end{array}$ & $\begin{array}{l}\text { Spring } \mathrm{BB} \% \\
\left(\mathrm{AAE_{BB }}=1.7\right)\end{array}$ & $\begin{array}{l}\text { Spring } \mathrm{BB} \% \\
\left(A \mathrm{AE}_{\mathrm{BB}}=2.0\right)\end{array}$ \\
\hline $\mathrm{LJ}$ & 51 & 32 & 31 & 20 \\
\hline $\mathrm{AJ}$ & 85 & 60 & 53 & 35 \\
\hline
\end{tabular}




\section{BC vertical profile measurements by ultralight aircraft over Ljubljana}

Black carbon vertical profiles (Figure S3) were measured in the Ljubljana basin using an ultralight airplane (Aerospool Dynamic WT9; see GLWF, 2019). The air was sampled using an isokinetic inlet and a modified version of the Aethalometer AE33 with 1 second time resolution (Drinovec et al., 2015). The location of the inlet prevented self-pollution from the airplane exhaust and the inlet was designed to be iso-kinetic at the airplane airspeed. The inlet is a conical diffusor, mounted on the holder of the Pitot tube under the wing, and designed for airspeed $240 \mathrm{~km} / \mathrm{h}$. The plane followed the helical path between $400 \mathrm{~m}$ and $1100 \mathrm{~m}$ ASL (100 - $800 \mathrm{~m} \mathrm{AGL).} \mathrm{The} \mathrm{BC} \mathrm{concentration} \mathrm{was} \mathrm{used} \mathrm{as} \mathrm{a} \mathrm{parameter}$ quantifying the influence of ground sources on the primary air pollution in the mixing layer and the mixing layer height was estimated from $\mathrm{BC}$ vertical profiles. The measured data was fitted using a Boltzmann function:

$$
y=\frac{A_{1}-A_{2}}{1+e^{\left(x-x_{0}\right) / d x}}+A_{2},
$$

where $\mathrm{x}_{0}$ represents the mixing layer height $(\mathrm{MLH})$. Comparison of $\mathrm{MLH}$ determined by plane measurements and Rn-model are presented in Table $\mathrm{S} 2$.

Table S2: Summary of MLH determined from BC vertical profile measured by plane and MLH determined by $\mathrm{Rn}$ box model (data for the closest hour is reported).

\begin{tabular}{|l|c|c|}
\hline Date \& time (UTC) & $\begin{array}{c}\text { BC vertical profile MLH } \\
\text { (m a.s.I) / (m a.g.l.) }\end{array}$ & $\begin{array}{c}\text { Radon model MLH } \\
\text { (m a.g.l.) }\end{array}$ \\
\hline $16 / 02 / 201715: 03$ & $712 \pm 3 / 412 \pm 3$ & 453 \\
\hline $09 / 03 / 20177: 40$ & $481 \pm 1 / 181 \pm 1$ & 264 \\
\hline $15 / 03 / 20177: 10$ & $460 \pm 2 / 160 \pm 2$ & 127 \\
\hline $19 / 05 / 20195: 10$ & $490 \pm 3 / 190 \pm 3$ & 196 \\
\hline
\end{tabular}



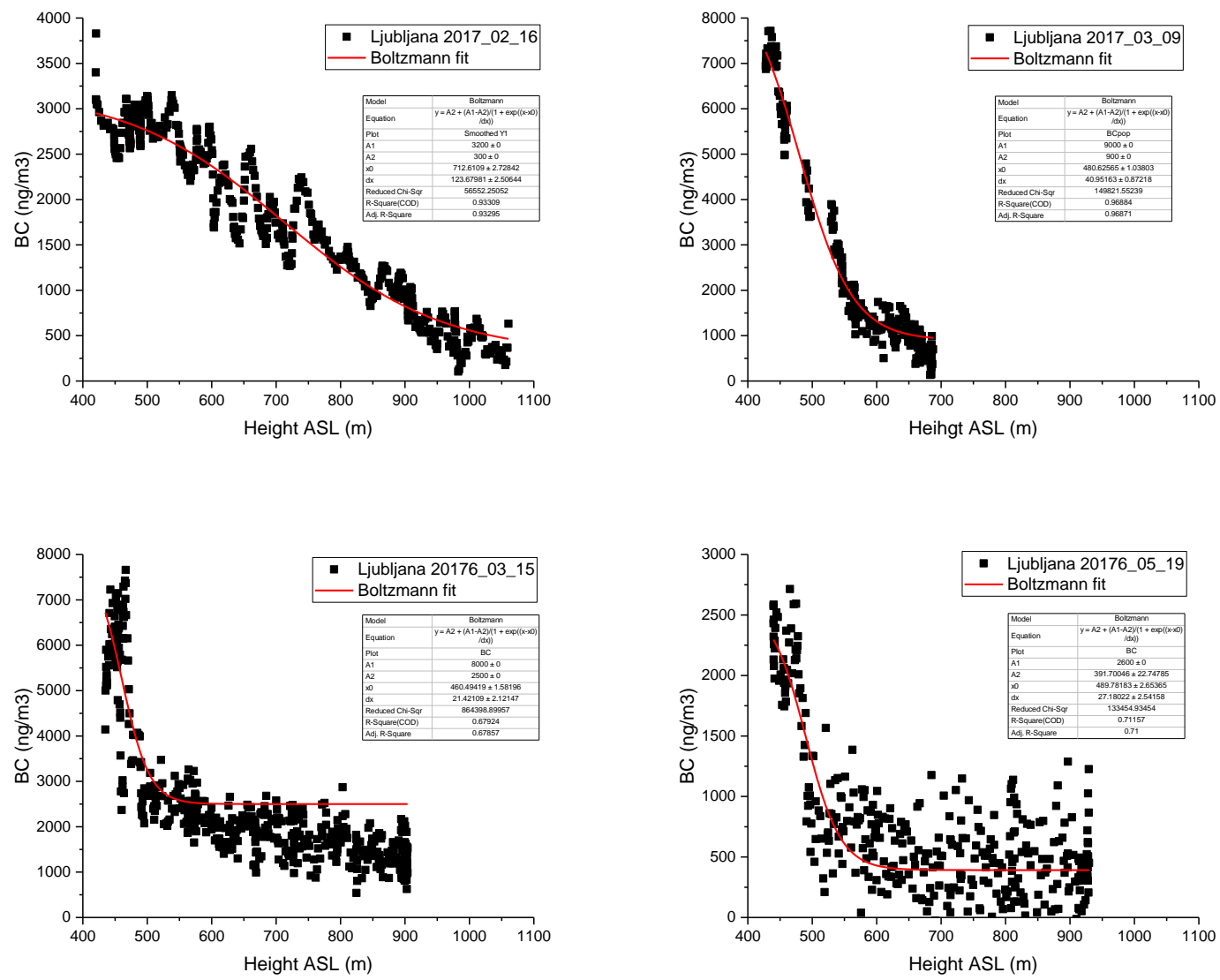

Figure S3: Black carbon vertical profiles above Ljubljana at different conditions of atmospheric stability. 


\section{Local wind conditions}
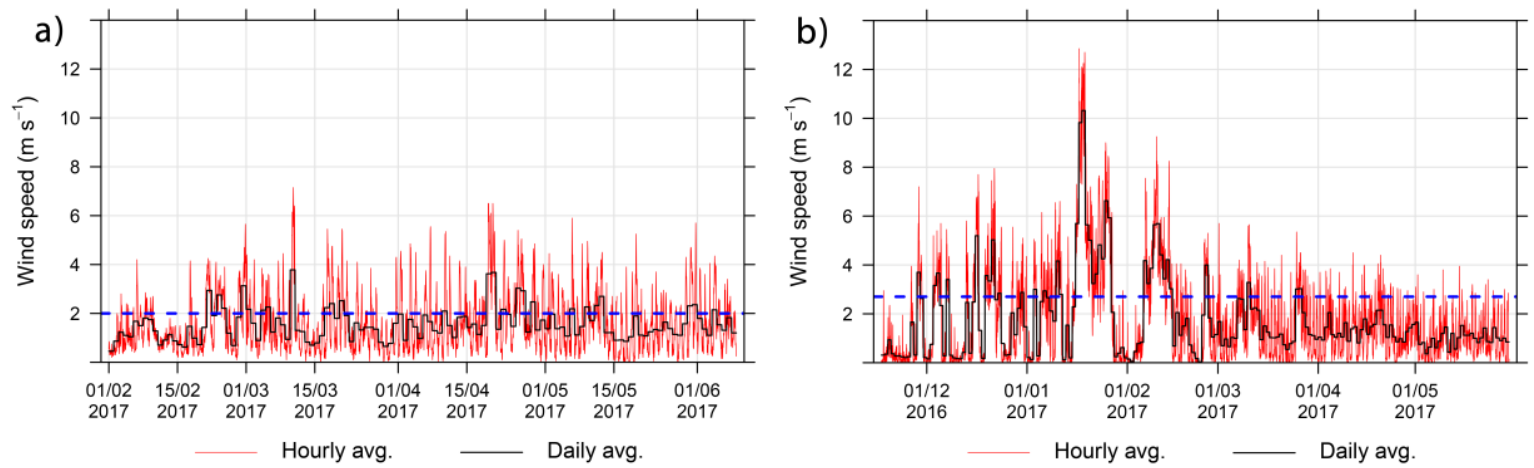

Figure S4: Time series of hourly and daily average wind speeds (ws) for Ljubljana (a) and Ajdovščina (Vipava valley) (b). Dashed blue line represent daily average wind speed at $80^{\text {th }}$ percentile of all data distribution. Days, when daily average ws exceeds the limit value of $2 \mathrm{~m} \mathrm{~s}^{-1}$ and $2.7 \mathrm{~m} \mathrm{~s}^{-1}$ for Ljubljana and Ajdovščina, respectively, are not considered in the analyses.
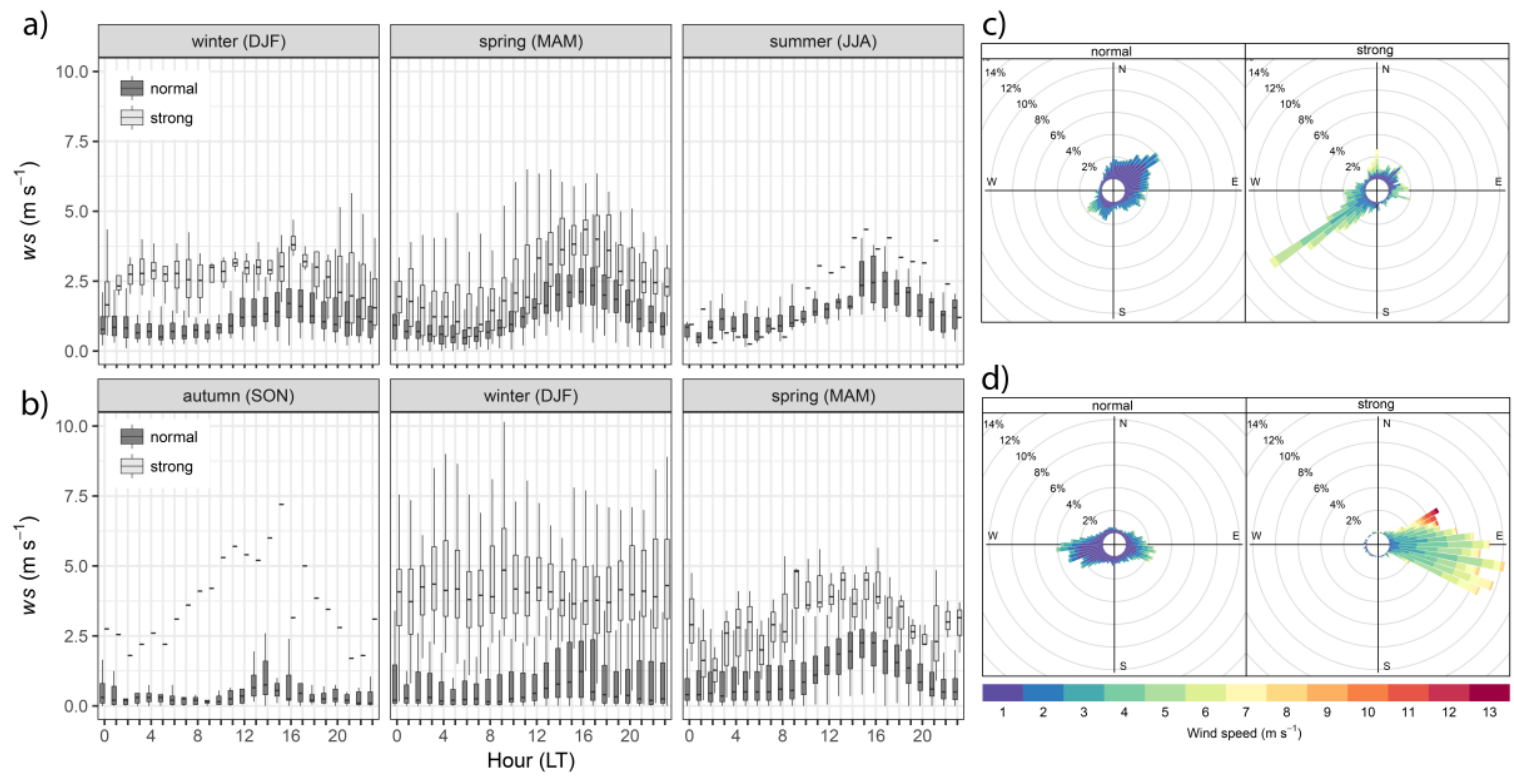

Figure S5: Diurnal variation of wind speed (ws) for normal and strong wind conditions for Ljubljana (a) and Vipava valley (b), grouped by season, and corresponding wind roses for Ljubljana (c) and Vipava valley (d). 


\section{Smoothing of $R n$ concentration $\left(C_{R n}\right)$ measurements}
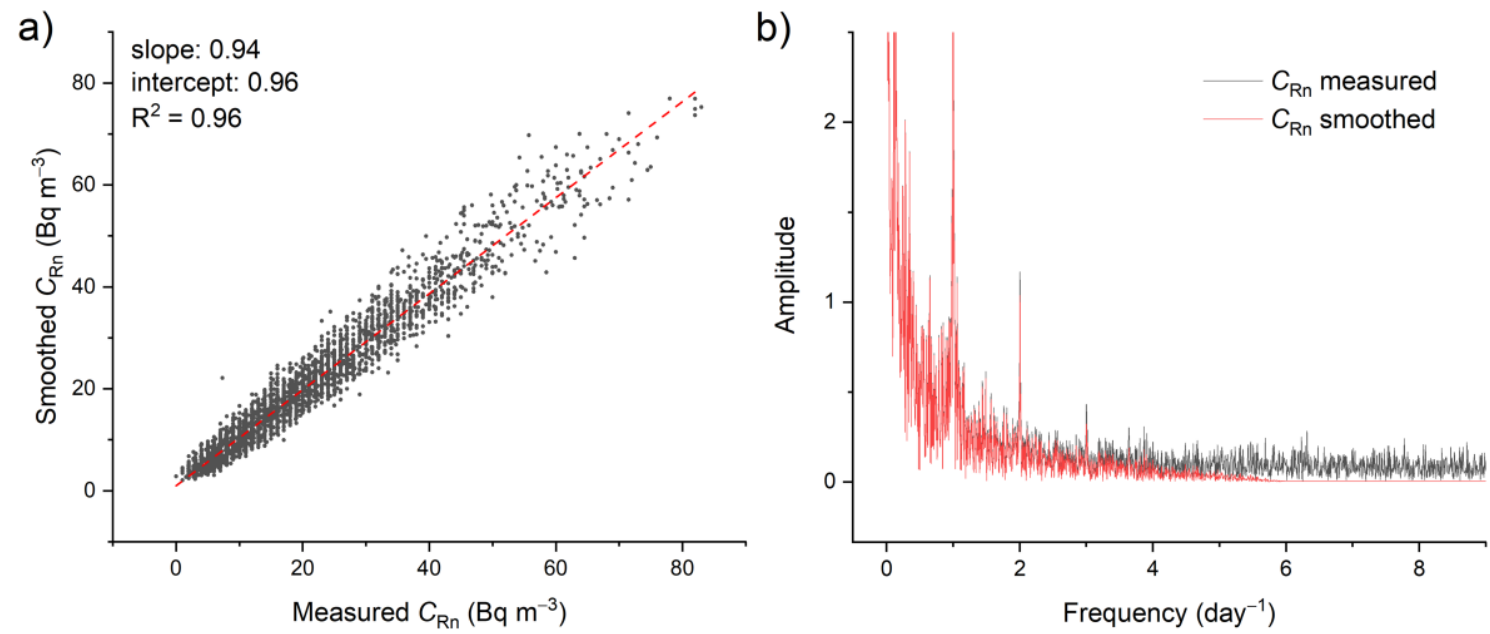

Fig. S6: a) Linear regression between measured $C_{R n}$ and smoothed $C_{R n}$ data for Ljubljana. b) FFT filter with cut-off frequency of $0.25 \mathrm{~h}^{-1}$ was applied to raw data.

\section{Sensitivity analyses of spatial decay constant}

Sensitivity analyses of modelled $E_{\mathrm{TR}}$ for different $\gamma_{T R}$ values were performed based on comparison with measured traffic density at representative street section, which connects two of Ljubljana arteries leading from the ring to the city center (Figure S7). Traffic during working days in Ljubljana is characterized by two significant peaks, morning peak between 7:00 and 9:00 and afternoon peak between 15:00 and 17:00. The fraction of freight vehicles is higher in morning hours, whereas mainly car traffic is characteristic for afternoon hours. After 17:00 traffic density decreases towards midnight and is the lowest between midnight and 4:00. Sunday diurnal pattern significantly differs from working days by about $50 \%$ smaller traffic density and the missing morning peak.

Linear regression (presented as $\mathrm{R}^{2}$ ) between normalized traffic density (normalized by mean) diurnal profile and normalized $E_{\mathrm{TR}}$ diurnal profile (normalized by median values) for different choice of spatial decay constant $\left(\gamma_{\mathrm{TR}}\right)$ is presented on Figure $\mathrm{S} 8$ and $\mathrm{S} 9 \mathrm{~b}$. The strength of correlation is the highest for $\gamma_{\text {TR }}$ selection between $5 \times 10^{-5} \mathrm{~m}^{-1}$ and $7 \times 10^{-5} \mathrm{~m}^{-1}$ (points marked with " $\mathrm{B}$ ", " $\mathrm{C}$ " and " $\mathrm{D}$ " on Figure S9 b). As shown by diurnal evolution (in terms of median $E_{\mathrm{TR}}$ ) on Figure $\mathrm{S} 9 \mathrm{c}$, the reason for weaker correlation with traffic density for point " $G$ " is the overestimation of $E_{\mathrm{TR}}$ in the afternoon hours, which is caused by stronger wind speeds in afternoon hours. Decreasing $\gamma_{\mathrm{TR}}$ from " $\mathrm{D}$ " to "B" would cause $23 \%$ lower median $E_{\mathrm{TR}}$ calculated for the afternoon peak emissions at 15:00, where the highest model uncertainty is expected. On the other hand, increasing $\gamma_{T R}$ from " $D$ " to " $G$ " would result in $36 \%$ higher $E_{\mathrm{TR}}$ for the same time period. 

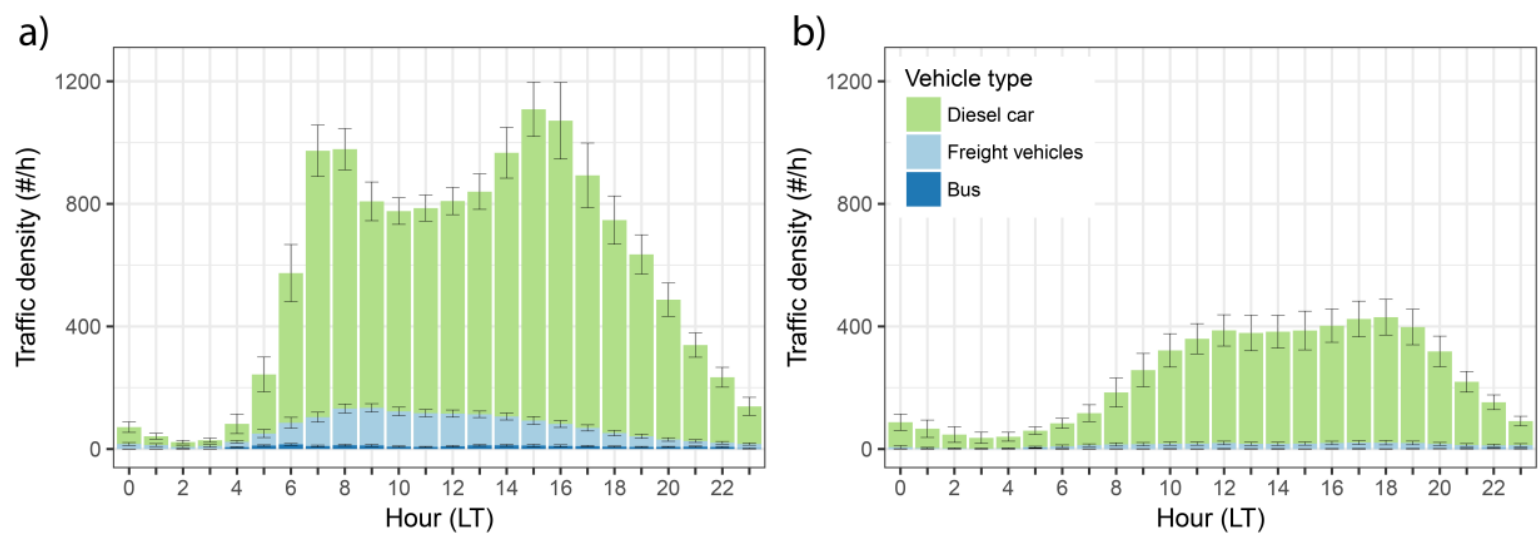

Figure S7: Mean traffic density (and standard deviation) for working days (a) and Sundays (b) for diesel cars, freight vehicles and buses. The ratio between gasoline and diesel cars in Slovenia is 55 (gasoline):45(diesel) (Si-Stat, 2019).

a)

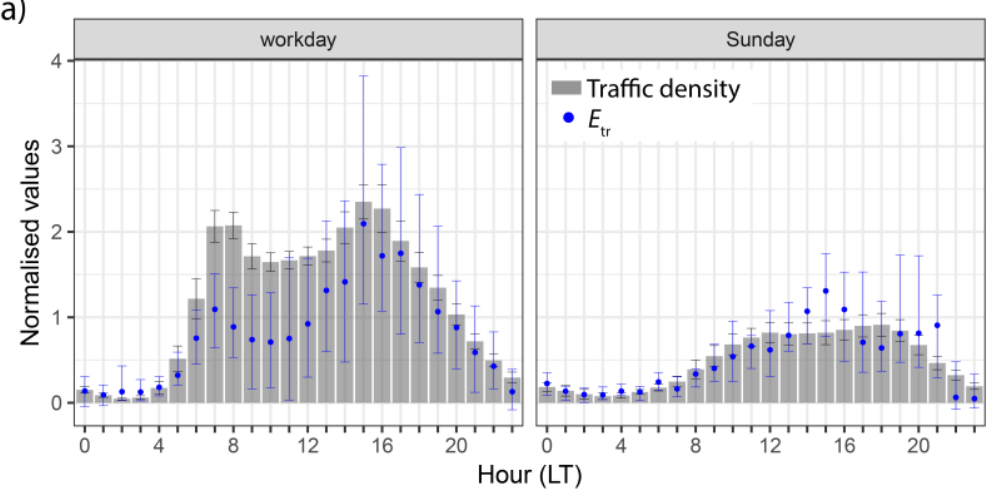

b)

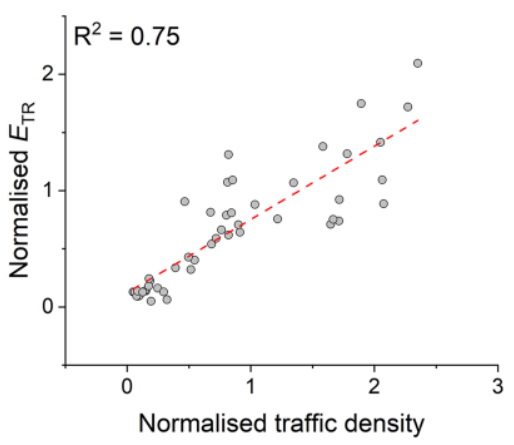

Figure S8: Comparison between diurnal profiles of traffic density and modelled $E_{\mathrm{TR}}$ in Ljubljana. Normalized mean hourly values are presented for traffic density, whereas $E_{\mathrm{TR}}$ values are presented in terms of normalized median, $25^{\text {th }}$ and $75^{\text {th }}$ quantile (a). Linear regression of points that are presented on the diurnal plot results in $R^{2}=0.75$. 
a)

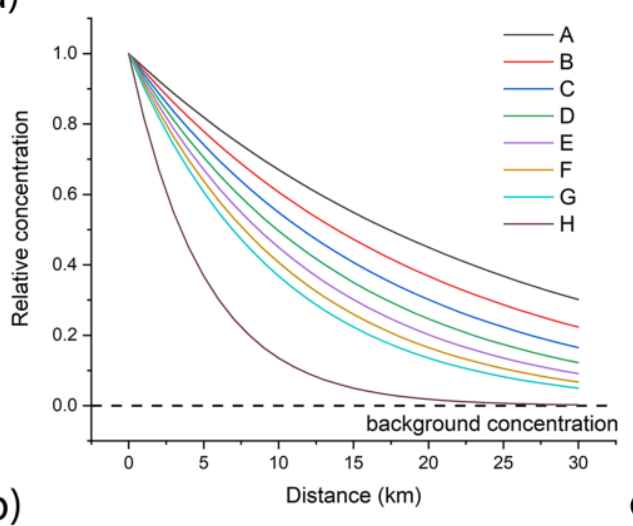

\begin{tabular}{|l|c|}
\hline Label & $\gamma\left(\mathbf{m}^{-\mathbf{1}}\right)$ \\
\hline $\mathrm{A}$ & $4 \times 10^{-5}$ \\
\hline $\mathrm{B}$ & $5 \times 10^{-5}$ \\
\hline C & $6 \times 10^{-5}$ \\
\hline D & $7 \times 10^{-5}$ \\
\hline E & $8 \times 10^{-5}$ \\
\hline F & $9 \times 10^{-5}$ \\
\hline G & $1 \times 10^{-4}$ \\
\hline H & $2 \times 10^{-4}$ \\
\hline
\end{tabular}

b)

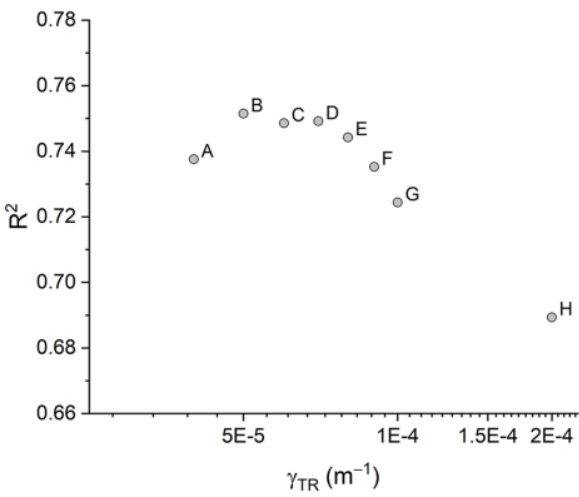

c)

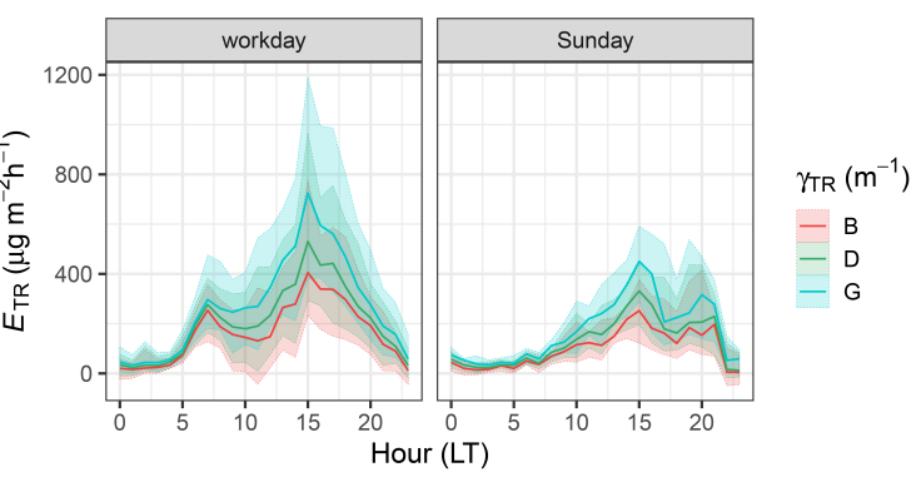

Figure S9: Dependence of modelled $E_{\mathrm{TR}}$ on the choice of horizontal advection term. a) Spatial decrease of $\mathrm{BC}$ concentration from the source by different $\gamma$. Labels are explained in the table. b) Dependence of $\mathbf{R}^{2}$ for correlation between normalized diurnal profile of traffic density and normalized diurnal profile (in terms of median hourly values) of modelled $E_{\mathrm{TR}}$ for Ljubljana. c) Diurnal profile of modelled $E_{\mathrm{TR}}$ for selected cases of $\gamma_{\mathrm{TR}}$ for Ljubljana: line - median, shaded area $25^{\text {th }}$ to $75^{\text {th }}$ quantile. 


\section{References}

Drinovec, L., Močnik, G., Zotter, P., Prévôt, A. S. H., Ruckstuhl, C., Coz, E., Rupakheti, M., Sciare, J., Müller, T., Wiedensohler, A., and Hansen, A. D. A.: The "dual-spot" Aethalometer: an improved measurement of aerosol black carbon with real-time loading compensation, Atmos. Meas. Tech., 8, 1965-1979, 10.5194/amt-8-1965-2015, 2015.

GLWF: https://www.worldgreenflight.com/, access: May 27, 2019.

Kumar, N. K., Corbin, J. C., Bruns, E. A., Massabó, D., Slowik, J. G., Drinovec, L., Močnik, G., Prati, P., Vlachou, A., Baltensperger, U., Gysel, M., El-Haddad, I., and Prévôt, A. S. H.: Production of particulate brown carbon during atmospheric aging of wood-burning emissions, Atmos. Chem. Phys., 18, 1784317861, 10.5194/acp-18-17843-2018, 2018.

Sandradewi, J., Prévôt, A. S. H., Szidat, S., Perron, N., Alfarra, M. R., Lanz, V. A., Weingartner, E., and Baltensperger, U.: Using aerosol light absorption measurements for the quantitative determination of wood burning and traffic emission contributions to particulate matter, Environ. Sci. Technol., 42, 3316-3323, 10.1021/es702253m, 2008.

Statistical Office of Republic of Slovenia (Si-Stat): https://pxweb.stat.si/SiStat, access: June 24, 2019, 2019.

Zotter, P., Herich, H., Gysel, M., El-Haddad, I., Zhang, Y., Močnik, G., Hüglin, C., Baltensperger, U., Szidat, S., and Prévôt, A. S. H.: Evaluation of the absorption Ångström exponents for traffic and wood burning in the Aethalometer-based source apportionment using radiocarbon measurements of ambient aerosol, Atmos. Chem. Phys., 17, 4229-4249, 10.5194/acp-17-4229-2017, 2017. 